\title{
CLIMATIC FACTORS ON THE ARCHEAN EARTH
}

\author{
JAMES C. G. WALKER
}

Space Physics Research Laboratory, The Department of Atmospheric and Oceanic Science, The University of Michigan, Ann Arbor, MI 48109 (U.S.A.)

(Received May 12, 1982)

\section{ABSTRACT}

Walker, J. C. G., 1982. Climatic factors on the Archean earth. Palaeogeogr., Palaeoclimatol., Palaeoecol., 40: 1-11.

There is no strong evidence for extreme climates during the Archean. Glaciogenic rocks are rare, while evaporites are about as widespread as in later geological periods. Sedimentary rocks suggest processes of erosion and weathering not particularly anomalous. This finding is surprising in the light of simple physical reasons to believe that the sun was less bright.

Although the area of exposed land was probably low, the albedo change associated with more extensive oceans could hardly have been large enough to prevent global glaciation. A stronger atmospheric greenhouse is indicated. Carbon dioxide was the most likely candidate gas. A variety of arguments suggest that it was much more abundant. Methane is another possible contributor to the greenhouse. While abiotic sources of this gas were probably negligible then as now, biogenic sources could have sustained methane mixing ratios in the range $10^{-4}$ to $10^{-r}$.

Other climatic factors of uncertain impact include more rapid rotation of the earth the length of the day was probably about fifteen hours throughout most of Archean time and little or no continental land areas, which would have reduced the importance of landsea circulations while permitting less restricted zonal flow of ocean currents.

\section{INTRODUCTION}

The Archean earth provides a useful opportunity to test our understanding of climatic theory. Factors that control climate were sufficiently different from those of the present day to make the test a challenge, but the differences were not nearly as great as those between the present-day earth and any of the planets. The study of Archean climate is therefore more likely to contribute to our understanding of the present terrestrial climate. The data on Archean climate are few, so the questions that can be posed are necessarily imprecise. In spite of this, many of the questions are by no means trivial to answer, and most of them have not yet been explored.

Although distant in time, environmental conditions on the Archean earth are immediately relevant to the biosphere of today. Biological evolution proceeds in directions that are controlled, to a large extent, by the environment. 
Major developments in the metabolic capabilities of organisms occurred during the Archean, and these developments made possible all subsequent biological evolution. The Archean climate is one link in the long chain of factors, processes, and events that has brought us here today.

This paper offers an overview of what is known or inferred about the climate on the Archean earth. Many of the topics I shall discuss are presented in greater detail in Walker et al. (1982). Another useful reference is Frakes (1979). Our knowledge and understanding of the Archean climate is at present fragmentary. There are few hard data, and much room for disagreement in their interpretation. My account must therefore be viewed as speculative and tentative. There is every reason to suppose, however, that more observational and theoretical research will yield much improved knowledge and understanding of the Archean climate.

\section{GEOLOGIC RECORD}

A record of ancient climates is likely to be found only in sedimentary rocks. Rocks of Precambrian age are preserved only in continental cratons, and only half a dozen or so small cratons of Archean age have yet been discovered (Lowe, 1980). The record of Archean climate is therefore not extensive, but it is by no means nonexistent. The end of the Archean was marked by extensive cratonization and growth of continental land areas. From that time on the record is potentially very good, but there has been little analysis yet of what that record may tell us about climatic factors.

Fig.1 summarizes the distribution in time of climatically informative features of the geologic record, as it is now known. The heavy line distinguishes between the Archean, with its sparse rock record, and the Proterozoic and later eras with an abundant record. The oldest rocks yet found date from $3.8 \mathrm{Ga}$ ago and are at Isua in West Greenland. There is, as yet, no terrestrial record of the first $800 \mathrm{Ma}$ of earth history. The Isua rocks include chemical

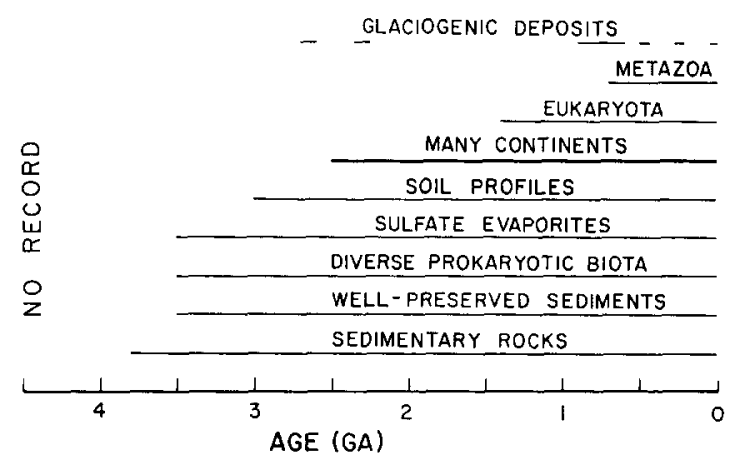

Fig.1. The extent of the geologic record of several indicators of climate. The rock record is sparse before the appearance of extensive continental land areas at the end of the Archean. 
and detrital sediments; waterborne processes of erosion, transport, and sedimentation were operative $3.8 \mathrm{Ga}$ ago. The Isua sediments, however, are heavily metamorphosed. The oldest well-preserved sediments are found in the Pilbara Block of Western Australia and the Barberton Mountain Land of South Africa; they date from $3.5 \mathrm{Ga}$ ago. These rocks contain the first evidence yet found of a diverse prokaryotic microbiota. The presence of life sets severe constraints on climate. The known record of evaporitic sulfate deposits dates back also to $3.5 \mathrm{Ga}$ ago. It indicates, at least, that there were arid areas on the globe. The record of ancient soil profiles, paleosols, has as yet been little explored; the oldest yet reported dates from $3 \mathrm{Ga}$ ago. Soil profiles can potentially yield information on weathering and transport processes. The known records of eukaryotic microorganisms and Metazoa begin during the Proterozoic. These more advanced forms of life set even tighter climatic constraints than the earlier prokaryotic biota.

These diverse forms of historical evidence reveal many indications of changing environmental chemistry; the rocks being weathered were changing from basaltic in composition to granitic, and atmospheric composition was changing from more reducing to more oxidizing. But none of the features of the geologic record yet described provide any indication of climates in the Precambrian that were different from those of the Phanerozoic. There are no features of the known rock record, as presently interpreted, that require a secular change in climate. Only the record of glaciogenic deposits, which appears at the top of Fig.1, suggests a possibly warmer climate. This suggestion is based on the paucity of glaciogenic deposits in the Precambrian, and particularly on the long interval in the Middle Proterozoic from which no undisputed glaciogenic rocks have yet been found (Hambrey and Harland, 1982). There is no firm record of glacial deposits in the Archean; the nature of the Witwatersrand deposits of $2.65 \mathrm{Ga}$ ago is still subject to debate. It is not clear whether glaciogenic deposits are rare in the Precambrian because they did not form, because they have not been preserved, or because they have not yet been recognized. If the record is reasonably complete, then either the Precambrian climate was generally warmer, or it was less subject to whatever instability causes glacial ages.

\section{LIMITS ON TEMPERATURE}

With the possible exception of glaciogenic deposits, then, the rock record provides no evidence of an Archean climate that was significantly different from the climates of the more recent geologic past. What constraints on temperature can be deduced from the rock record? In considering this question it is necessary to distinguish between global average temperature, a parameter of many simple climatic theories, and the temperature at which a particular rock, preserved and now available for examination, was deposited. Some aspects of the record refer to specific, unknown locations on the globe; other aspects can be interpreted in terms of global average temperature. 
In attempting to deduce a temperature history for the Precambrian earth, we can, in my view, disregard the interpretation of their data on the oxygen isotopic composition of cherts offered by Knauth and Epstein (1976). This interpretation does not adequately address the possibility of a secular change in the isotopic composition of sea water that probably accompanied cratonization. Neither does it adequately consider late diagenetic changes in the isotopic composition of the cherts themselves.

Less debatable is the geological evidence for the presence of liquid water on the surface of the globe since the $3.8 \mathrm{Ga}$ old Isua time. Although a massive steam atmosphere overlying a liquid water ocean may be possible, it seems most likely that the global average temperature has not exceeded $100^{\circ} \mathrm{C}$ since the known rock record began. This limit is shown in Fig.2. The presence of diverse life since at least $3.5 \mathrm{Ga}$ ago indicates clearly that the earth has not been everywhere frozen. It sets an upper limit on temperature also, but the precise value of this limit is hard to define. Only specialized prokaryotic microbes can survive high temperatures. If early life had adapted to generally high temperatures we might expect a more widespread distribution in the biota of the heat-tolerant enzymes that characterize thermophilic bacteria. Eukaryota and Metazoa are less tolerant of high temperatures than Prokaryota; the broken line in Fig.2 is probably a generous upper limit on the global average temperature consistent with the fossil record.

As already noted, the presence of evaporite minerals back to $3.5 \mathrm{Ga}$ ago shows that there were arid locations on the globe. The fact that many of the deposits were precipitated originally as gypsum sets an upper limit on the temperature at these locations. Gypsum is converted to anhydrite at temperatures

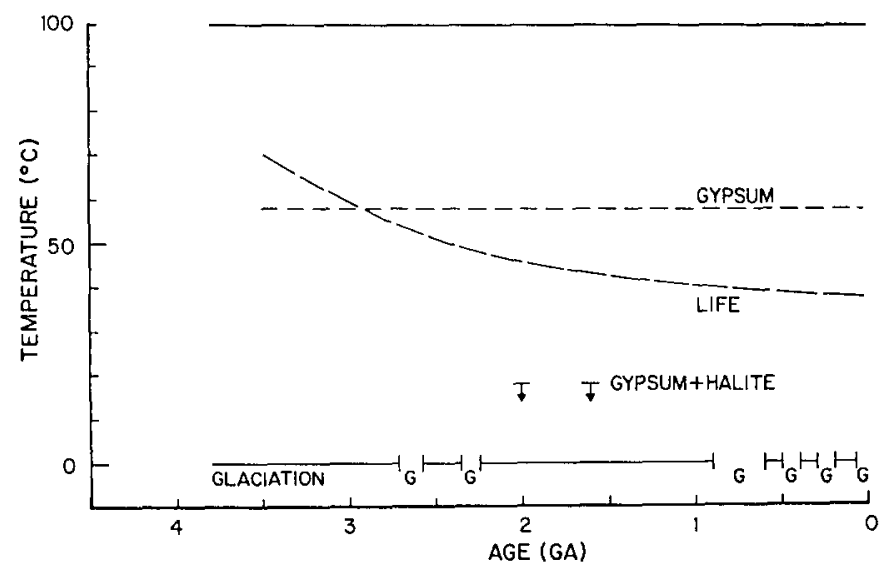

Fig.2. Limits on the history of surface temperature implied by various aspects of the geologic record. The presence of liquid water has set limits of $100^{\circ} \mathrm{C}$ and $0^{\circ} \mathrm{C}$, except possibly during the glacial periods indicated by the letters $G$. The broken and dashed lines refer to upper limits. The points labelled gypsum + halite are upper limits referring to specific locations where it appears that these two evaporite minerals were precipitated simultaneously. 
above about $58^{\circ} \mathrm{C}$ in pure water and at lower temperatures in saline water (Holland, 1978). The identification of evaporitic gypsum throughout Precambrian time, therefore, sets an upper limit of $58^{\circ} \mathrm{C}$ on temperatures in evaporite basins.

The continuing presence of liquid water sets a lower limit of $0^{\circ} \mathrm{C}$ on temperature; consideration of the ice-albedo feedback instability (North, 1975; Budyko, 1977) would raise this lower limit somewhat. Perhaps, on the other hand, the limit should be lowered during the infrequent glacial intervals indicated by $G$ in Fig.2.

\section{COOL SUN}

The absence of ice is probably the central problem of the Archean climate. The conclusion that the luminosity of the young sun was smaller (Sagan and Mullen, 1972) is not a marginal effect of minor details of models of solar evolution (Gough and Weiss, 1976; Gough, 1977; Newman and Rood, 1977). The argument for an increase in solar luminosity with time goes like this: As the sun ages it converts hydrogen to helium; the increased mean molecular weight of solar material causes an increase in the central temperature and pressure in accordance with the virial theorem; an increase with time in the rate of generation of energy is the result. There are differences in detail between different theories of solar evolution over how far the conversion of hydrogen to helium has gone and therefore how much the solar luminosity has increased with time. According to Newman and Rood, the average of a number of evolutionary models yields a ratio of present luminosity to initial luminosity of 1.3. Gough favors a value of 1.4 for this ratio. According to Gough and Weiss, the increase has resulted largely from an increase in the radius of the photosphere; the temperature of the photosphere has changed very little, so there has presumably been little change in the spectral composition of solar visible and infrared radiation. The central problem of the Archean climate is therefore to explain how earth remained warm when the sun was substantially less luminous. In a later section I shall show that the climatic impact in the Archean of gravitational energy released during the course of earth accretion and internal differentiation is negligible.

The lowest line in Fig. 3 shows the evolution of earth's effective temperature for a presumed increase in solar luminosity by a factor of 1.3 and the assumption of no change in planetary albedo. The effective temperature adequately represents what global average temperature would be if there were no atmospheric greenhouse. The albedo of the Archean earth is of course quite uncertain. There is good evidence that continental land areas, with their comparatively high albedos, were small or absent in the early Archean. This is not the place to discuss this evidence. [For reviews see Lowe (1980) and Schopf (1982).] The second line in Fig.3 shows effective temperature for the case of a planet completely covered by water. The largest contribution to the terrestrial albedo is made by clouds, and we can only 


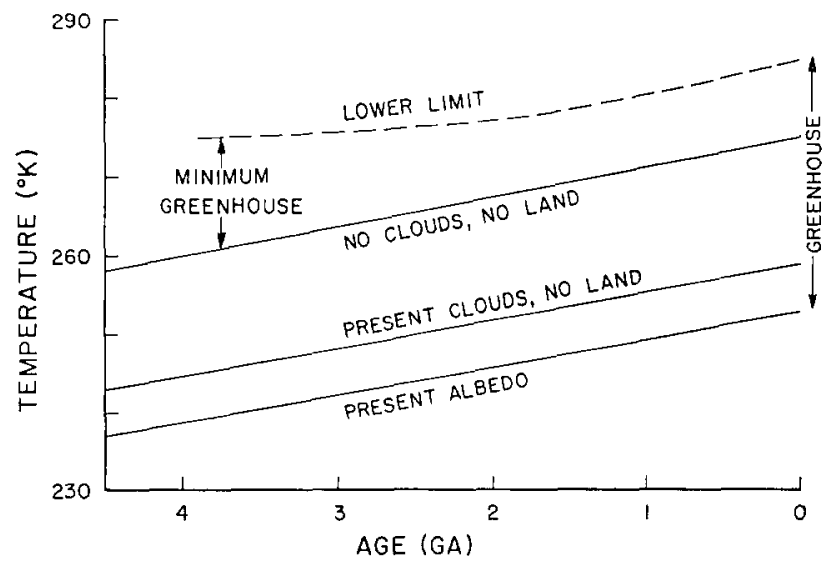

Fig.3. The evolution of terrestrial temperatures in response to increasing solar luminosity. The solid lines represent the effective temperature, or the temperature at which the planet radiates to space, for various assumptions concerning planetary albedo. The broken line is a lower limit on global average surface temperature consistent with the geologic record. The difference between effective temperature and surface temperature is a consequence of the atmospheric greenhouse.

guess at the cloud cover on the Archean earth. As an upper limit on effective temperature I show in Fig. 3 the case of a completely water covered earth with no clouds. Zero cloud cover in the presence of liquid water is hardly likely to be achievable.

The broken line in Fig. 3 shows a generous lower limit on global average temperature deduced from the geologic record. Actual temperatures are likely to have exceeded this limit. The difference between this lower limit and the effective temperature for whatever albedo seems most appropriate represents the effect of the atmospheric greenhouse. The magnitude of the greenhouse effect today is shown on the right of Fig.3. The minimum possible greenhouse in the early Archean is shown on the left. Uncertainties concerning cloud cover and hence albedo make it hard to extrapolate even simple climate models into the time of the cool sun, but it is clear that the atmospheric greenhouse has made an important contribution to climate since the beginning of the geologic record.

\section{ATMOSPHERIC GREENHOUSE}

In considering this problem further, I shall conservatively assume that the early Archean albedo corresponded to the present-day cloud cover and no land. This assumption is conservative in the following sense: we know that there was little or no land, and we know no clear reason for cloud cover to have been different. Evidence for early release of volatiles from the solid earth (Walker, 1977; Stevenson, 1982) suggests that atmospheric surface 
pressure (and the amount of water in the ocean) should have been little different from the present. The atmosphere probably consisted of nitrogen, with water, carbon dioxide, and traces of other gases. In our present state of knowledge, increased cloud cover, with an increased requirement on the atmospheric greenhouse, is no less likely than decreased cloud cover. So I shall assume no change in cloud cover.

With this assumption I compare contributions to the atmospheric greenhouse in Fig.4. This figure is based on the predictability of the variation of the water vapor greenhouse with surface temperature: higher temperatures yield higher water vapor concentrations in the atmosphere and therefore a larger greenhouse contribution due to water vapor (Walker et al., 1981). The situation for today is shown on the right of the figure. The effective temperature is about $253^{\circ} \mathrm{K}$ (Goody and Walker, 1972), the global average surface temperature is about $285^{\circ} \mathrm{K}$ (Sellers, 1965), water contributes about $30^{\circ}$ to the greenhouse effect, and other constituents contribute about $2^{\circ}$.

I consider three possible surface temperatures for a time $4 \mathrm{Ga}$ ago - warm, the same as today, and cool but not frozen. The effective temperature was $245^{\circ} \mathrm{K}$. For all three cases the contribution of atmospheric constituents other than water vapor to the greenhouse was larger than it is today. The necessary additional contribution to the greenhouse increases with increasing average surface temperature. I conclude that the water vapor greenhouse alone cannot solve the problem of the cool sun, unless cloud cover was less.

Possible additional contributions to the atmospheric greenhouse depend, of course, on atmospheric composition. In evaluating possible compositions

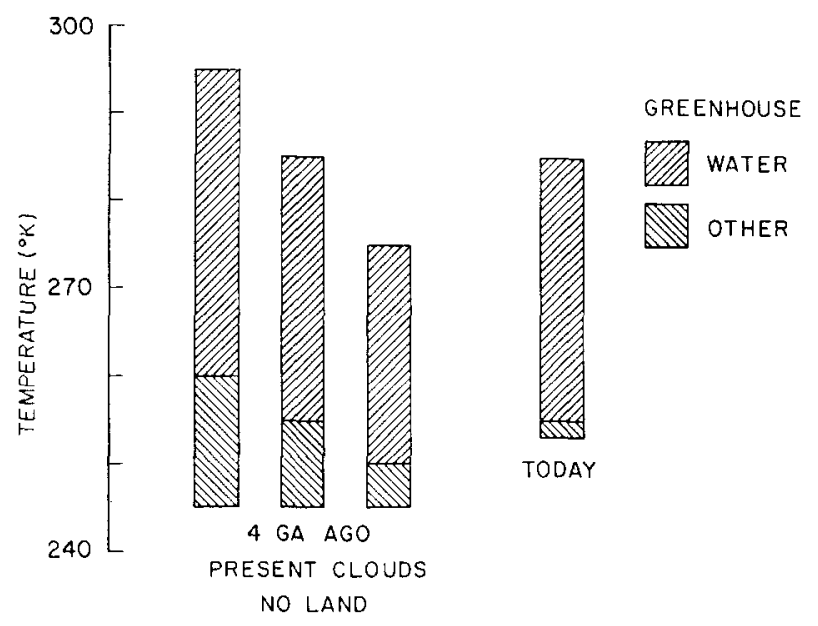

Fig.4. Contributions to the atmospheric greenhouse today and $4 \mathrm{Ga}$ ago, for three different assumptions concerning Archean surface temperature and a particular assumption concerning the planetary albedo in the Archean. The contribution to the greenhouse of atmospheric constituents other than water vapor must have been larger in the Archean than it is today in order to avoid an ice-covered earth. 
of the Archean atmosphere it is necessary to think in terms of the sources and sinks of atmospheric gases and their global geochemical cycles. All atmospheric constituents except nitrogen and the inert gases cycle through the atmosphere in times that are short in geological terms. In particular, because of an absence of sources, oxygen was not present in the Archean atmosphere (Kasting and Walker, 1981; Walker et al., 1982). Sagan and Mullen (1972) favored ammonia as the additional greenhouse gas in the early atmosphere. Because of the solubility of ammonia in water (Wigley and Brimblecombe, 1981 ) and because of its photochemical instability in even anoxic atmospheres (Kuhn and Atreya, 1979; Kasting, 1982), it is most unlikely that adequate concentrations of this gas could have been present. Methane is similarly susceptible to photochemical attack (Kasting, 1979), and is not likely to have made a large contribution to the atmospheric greenhouse. Aerosols are a possibility that have not been adequately explored; there is evidence of explosive volcanism in the Archean (Lowe, 1980), but the obvious choice for a gas to enhance the atmospheric greenhouse is carbon dioxide. Owen et al. (1979) showed that concentrations of carbon dioxide a few hundred times greater than those of today can provide the needed enhancement, and Walker et al. (1981) have described a negative feedback mechanism that could cause carbon dioxide partial pressure to adjust in such a way as to maintain clement temperatures at the surface of the earth.

It may be significant that the glaciogenic deposits of the Huronian formation of Canada (2.3 Ga ago) are underlain by sedimentary rocks that appear to have been deposited under a nonoxidizing atmosphere and are overlain by rocks that appear to have been deposited under oxidizing conditions (Roscoe, $1969,1973)$. This single datum suggests a contribution, possibly not large, of a reduced greenhouse gas that was swept out of the atmosphere by rising oxygen partial pressure. Calculations being carried out by Zahnle, Kasting, and Walker suggest methane as a candidate that might have achieved mixing ratios of $10^{-4}$ to $10^{-6}$ in the Archean atmosphere, large enough to contribute a few degrees to the atmospheric greenhouse. There is little likelihood of large methane concentrations or a large methane greenhouse effect in Archean times.

\section{OTHER CLIMATIC FACTORS}

\section{Continentality}

The growth of continental land areas at the end of the Archean has already been mentioned. Such continents as existed in the Archean were small and rare. The effect of this change on albedo and temperature has already been discussed, but the absence of continents no doubt had a profound effect on

global circulation also; monsoons, for example, would have been absent. From the point of view of climatic theory, the land-free earth should be easier to model. Exposed land and shallow water was present (Lowe, 1980), 
but probably mainly in the form of relatively small volcanic islands, not unduly restrictive of either oceanic or atmospheric circulation. There may, therefore, have been less meridional transport. Dry land was probably free of vegetation and may have had a high albedo (Walter, 1979).

\section{Rotation rate}

As shown in Walker et al. (1982) it is possible to extrapolate tidal drag in the earth-moon system back into the past with quite simple assumptions. If the moon has been in earth orbit for $4.5 \mathrm{Ga}$, the rate of dissipation of tidal energy must have been much smaller in the Precambrian than it is today. Could this reduced tidal dissipation rate have been due to the absence of extensive shallow seas? The theoretical rate of decrease of earth's rotation and the rate of recession of the moon are rapid at first, when the moon is close and tidal amplitudes are large. Calculations by Stevenson (Walker et al., 1982) show that the length of the day increases from 5 to $12 \mathrm{~h}$ in less than $0.5 \mathrm{Ga}$. Shorter periods of earth rotation can not last for longer periods of time. The length of the day was undoubtedly shorter in the Archean than it is at present, but it is hardly likely to have been less than $15 \mathrm{~h}$. Calculations by Hunt (1979) provide an indication of the effects of faster rotation, although he used a rotation rate that is not likely to have existed for any substantial period of time. Faster rotation inhibits meridional transport of heat, yields shorter horizontal scales for global circulation, and restricts the extent in latitude of the tropical circulation.

\section{Accretional heating}

The gravitational potential energy of the whole earth is such that accretion in a period of $10^{7}$ years would yield an energy flux comparable to the solar constant (Walker, 1982). Accretional energy can not therefore have made a significant contribution to global climate over the $1.3 \times 10^{9}$ years of the Archean era. Data from the planets indicate that heavy bombardment terminated prior to $3.9 \mathrm{Ga}$ ago (Taylor, 1975; Head et al., 1977; Head and Solomon, 1981). On both grounds, it seems that only solar luminosity can have made a significant contribution to the maintenance of earth's surface temperature.

\section{Solar ultraviolet radiation}

There is good reason to suppose that the young sun was more active (Zahnle and Walker, 1982). Chromospheric and coronal emissions should have been larger during the Archean, with the enhancements greatest for the shortest wavelengths. Evaluation of the climatic impact of these emissions awaits a clearer understanding of how solar activity affects climate. 


\section{CONCLUSION}

Presumably any successful climatic theory can be tuned to reproduce present conditions to a desired level of precision. To test a theory we need to see if it works also under different conditions. Planets represent a possible testing ground, but they tend to be too different from earth to provide a test of a single, unmodified theory. The terrestrial past is more promising in this respect, because the changes from the present are incremental. As we go further back in time, climatic factors change more, and the potential test of any climatic theory becomes more severe. The data, however, become more scarce and less precise. The climate on the Archean earth offers a good potential test of the lowest order features of climatic theory. For scientists with interdisciplinary inclinations, the Archean offers fascinating opportunities to explore the basic workings of the climate system without having to become deeply embroiled in detail.

\section{ACKNOWLEDGEMENTS}

This paper describes an aspect of the work of the Precambrian Paleobiology Research Group. My colleagues in PPRG have contributed data and ideas for which I am grateful. Preparation of this paper was supported, in part, by the National Aeronautics and Space Administration under grant number NAGW176.

\section{REFERENCES}

Budyko, M.I., 1977. Climatic Changes. Am. Geophys. Union, Washington, D.C., 261 pp. Frakes, L. A., 1979. Climates Throughout Geologic Time. Elsevier, Amsterdam, 310 pp. Goody, R. M. and Walker, J. C. G., 1972. Atmospheres. Prentice-Hall, Englewood Cliffs, N.J., 155 pp.

Gough, D. O., 1977. Theoretical predictions of variations of the solar output. In: O. R. White (Editor), The Solar Output and Its Variations. University of Colorado Press, Boulder, Colo., pp. 451-473.

Gough, D. O. and Weiss, N. O., 1976. The calibration of stellar convection theories. Mon. Not. R. Astron. Soc., 176: 589-607.

Hambrey, M.J. and Harland, W.B., 1982. Earth's Pre-Pleistocene Glacial Record. Cambridge University Press, in press.

Head, J. W. and Solomon, S. C., 1981. Tectonic evolution of the terrestrial planets. Science, 213:62-76.

Head, J. W., Wood, C. A. and Mutch, T. A., 1977. Geologic evolution of the terrestrial planets. Am. Sci., $65: 21-29$.

Holland, H.D., 1978. The Chemistry of the Atmosphere and Oceans. Wiley-Interscience, New York, N.Y., 351 pp.

Hunt, B. G., 1979. The effects of past variations of the Earth's rotation rate on climate. Nature, 281: 188-191.

Kasting, J. F., 1979. Evolution of Oxygen and Ozone in the Earth's Atmosphere. Dissertation, University of Michigan, Ann Arbor, Mich.

Kasting, J. F., 1982. Stability of ammonia in the primitive terrestrial atmosphere. J. Geophys. Res., 87: 3091-3098. 
Kasting, J. F. and Walker, J. C. G., 1981. Limits on oxygen concentration in the prebiological atmosphere and the rate of abiotic fixation of nitrogen. J. Geophys. Res., 86: $1147-1158$.

Knauth, L. P. and Epstein, S., 1976. Hydrogen and oxygen isotope ratios in nodular and bedded cherts. Geochim. Cosmochim. Acta, 40: 1095-1108.

Kuhn, W. R. and Atreya, S. K., 1979. Ammonia photolysis and the greenhouse effect in the primordial atmosphere of the Earth. Icarus, 37: 207-213.

Lowe, D. R., 1980. Archean sedimentation. Annu. Rev. Earth Planet. Sci., 8: 145-167.

North, G. R., 1975. Theory of energy-balance climate models. J. Atmos. Sci., 32: 20332043.

Owen, T., Cess, R. D. and Ramanathan, V., 1979. Enhanced $\mathrm{CO}_{2}$ greenhouse to compensate for reduced solar luminosity on early Earth. Nature, $277: 640-642$.

Newman, M. J. and Rood, R. T., 1977. Implications of solar evolution for the Earth's early atmosphere. Science, 198: 1035-1037.

Roscoe, S. M., 1969. Huronian rocks and uraniferous conglomerates in the Canadian Shield. Geol. Surv. Can. Pap., 68-40: 205 pp.

Roscoe, S. M., 1973. The Huronian Supergroup, a Paleoaphebian succession showing evidence of atmospheric evolution. Geol. Assoc. Can. Spec. Pap., 12: 31-48.

Sagan, C. and Mullen, G., 1972. Earth and Mars: Evolution of atmospheres and surface temperatures. Science, $177: 52-56$.

Schopf, J. W. (Editor), 1982. The Earth's Earliest Biosphere: Its Origin and Evolution. Princeton University Press, Princeton, N.J., in press.

Sellers, W. D., 1965. Physical Climatology. University of Chicago Press, Chicago, Ill., $272 \mathrm{pp}$.

Stevenson, D. J., 1982. The nature of the Earth prior to the rock record (The Hadean Earth). In: J. W. Schopf (Editor), The Earth's Earliest Biosphere: Its Origin and Evolution. Princeton University Press, Princeton, N.J., in press.

Taylor, S. R., 1975. Lunar Science: A Post-Apollo View. Pergamon Press, New York, N.Y.

Walker, J. C. G., 1977. Evolution of the Atmosphere. Macmillan, New York, N.Y., 318 pp.

Walker, J.C.G., 1982. The earliest atmosphere of the Earth. Precambrian Res., 17: 147171.

Walker, J. C. G., Hays, P. B. and Kasting, J. F., 1981. A negative feedback mechanism for the long-term stabilization of Earth's surface temperature. J. Geophys. Res., 86: 9776-9782.

Walker, J. C. G., Klein, C., Schidlowski, M., Schopf, J. W., Stevenson, D. J. and Walter, M. R., 1982. Environmental evolution of the Archean-Early Proterozoic Earth. In: J. W. Schopf (Editor), The Earth's Earliest Biosphere: Its Origin and Evolution. Princeton University Press, Princeton, N.J., in press.

Walter, M., 1979. Precambrian glaciation. Am. Sci., 67: 142.

Wigley, T. M. L. and Brimblecombe, P., 1981. Carbon dioxide, ammonia and the origin of life. Nature, 291: 213-215.

Zahnle, K. J. and Walker, J. C. G., 1982. The evolution of solar ultraviolet luminosity. Rev. Geophys. Space Phys., 20: 280-292. 